\title{
A Framework for Articulating and Measuring Individual Learning Outcomes from Participation in Citizen Science
}

\author{
Tina Phillips*, Norman Porticella ${ }^{\dagger}$, Mark Constas ${ }^{\dagger}$ and Rick Bonney ${ }^{*}$
}

\begin{abstract}
Since first being introduced in the mid 1990s, the term "citizen science"-the intentional engagement of the public in scientific research-has seen phenomenal growth as measured by the number of projects developed, people involved, and articles published. In addition to contributing to scientific knowledge, many citizen science projects attempt to achieve learning outcomes among their participants, however, little guidance is available for practitioners regarding the types of learning that can be supported through citizen science or the measuring of learning outcomes. This study provides empirical data to understand how intended learning outcomes first described by the informal science education field have been employed and measured within the citizen science field. We also present a framework for describing learning outcomes that should help citizen science practitioners, researchers, and evaluators in designing projects and in studying and evaluating their impacts. This is a first step in building evaluation capacity across the field of citizen science.
\end{abstract}

Keywords: learning outcomes; evaluation; informal science learning

\section{Introduction}

Citizen science, defined here as public participation in scientific research, was originally conceived as a method for gathering large amounts of data across time and space (Bonney et al. 2009b). For decades or even centuries, citizen science has contributed to knowledge and understanding about far-ranging scientific topics, questions, and issues (Miller-Rushing et al. 2012). More recently, citizen science practitioners-those who conceive, develop, and implement citizen science projects-have sought not only to achieve science research outcomes but also to elicit learning and behavioral outcomes for participants (Bonney et al. 2016; Phillips et al. 2014).

Many proponents of citizen science argue that participating directly in the scientific process via citizen science is an excellent way to increase science knowledge and literacy (Bonney et al. 2016; Fernandez-Gimenez et al. 2008; Jordan et al. 2011; Krasny and Bonney 2005); understand the process of science (Trautmann et al. 2012; Trumbull et al. 2000); and develop positive action on behalf of the environment (Cornwell and Campbell 2012; Cooper et al. 2007; Lewandowski and Oberhauser 2017; McKinley et al. 2016). While some projects have demonstrated achievement of a few learning outcomes (see Bonney et al. 2016 for examples), most projects have yet to document robust outcomes such as increased interest in science or

\footnotetext{
* Cornell Lab of Ornithology, US

† Cornell University, US

Corresponding author: Tina Phillips (tina.phillips@cornell.edu)
}

the environment, knowledge of science process, skills of science inquiry, or stewardship behaviors (Bela et al. 2016; Bonney et al. 2016; Jordan et al. 2012; Phillips et al. 2012). Several factors may account for the lack of demonstrated and measurable learning outcomes. First, the field of citizen science is still young. Few if any specific outcomes have been defined or described by the field, therefore, project designers may not have clear concepts of what types of learning they are attempting to foster. In addition, measuring learning requires dedicated time, resources, and expertise in conducting social science research or evaluations, which many citizen science projects lack. As a result, citizen science suffers from a lack of quality project evaluations and cross-programmatic research (Phillips et al. 2012).

The informal science learning community recently developed guidance including tools and resources for evaluating learning outcomes from participation or engagement in informal science education (ISE) activities (Friedman et al. 2008; National Research Council 2009). These tools and resources are relevant to the field of citizen science, because many citizen science projects operate in informal environments such as private residences, parks, science and nature centers, museums, community centers, afterschool programs, or online. In addition, many citizen science projects are funded through ISE initiatives because the projects are expected to foster lifelong science learning (Crain et al. 2014). Therefore, tools developed to measure learning outcomes resulting from ISE can serve as logical starting points for evaluating outcomes of citizen science participation. 
The objectives of the research presented in this paper were to determine and describe the types of learning outcomes that are intended by citizen science project developers, to examine the alignment of these outcomes with informal science learning frameworks and guidelines, and to develop and present a new framework for articulating citizen science learning outcomes. We believe that the framework will help citizen science practitioners to design projects that achieve measurable learning. We also hope that the framework will facilitate cross-programmatic research to help the citizen science field show how its projects are impacting science and society. Our research further sought to determine the extent to which citizen science learning outcomes have been evaluated across the field, as a first step toward our overall goal of deepening evaluation capacity for the citizen science community.

\section{Citizen Science and Informal Science Learning}

The educational underpinnings of citizen scienceparticularly when involving adults-draw heavily from Informal Science Education (ISE), what Falk and Dierking (2003) refer to as "free-choice learning"-lifelong,

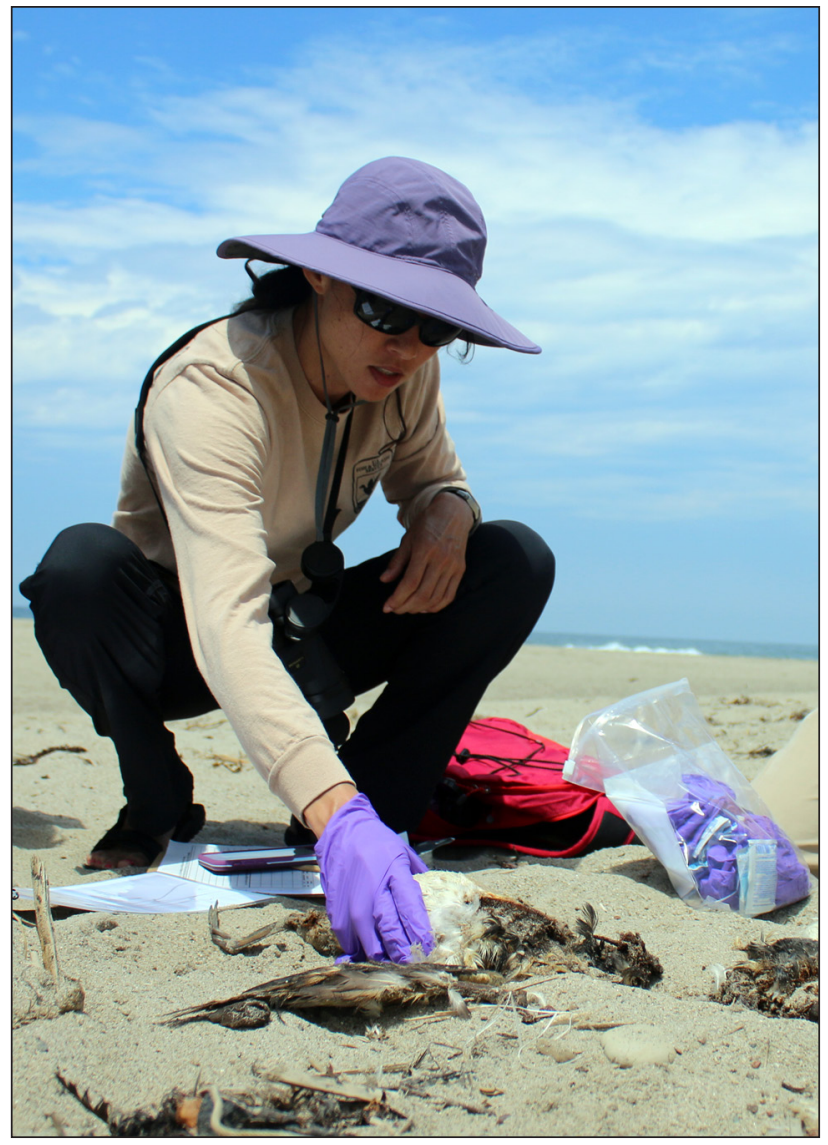

Figure 1: Participants in citizen science engage in a large number of activities such as designing studies, collecting and analyzing data, and disseminating project results. What do project designers hope that participants will learn from their participation? How are desired learning outcomes designed? How are they measured?

Credit: No copyright. Pacific Southwest Region USFWS/ Flickr/Public Domain. self-directed learning that occurs outside K-16 classrooms. Two influential documents from the ISE field provided a starting point for our study. The Framework for Evaluating Impacts of Informal Science Education Projects (Friedman et al. 2008), supported by the National Science Foundation (NSF), was the first publication produced by the ISE field that described a "standard" set of learning outcomes (referred to as impact categories) that could be used to systematically measure project-level outcomes. (We will refer to this publication as the "ISE Framework" for the remainder of this paper.) A major goal of the framework was to facilitate cross-project and cross-technique comparisons of the impacts of ISE projects on public audiences. The five impact categories are:

- Knowledge, awareness, or understanding of Science, Technology, Engineering, and Math (STEM) concepts, processes, or careers

- Engagement or interest in STEM concepts or careers

- Attitude toward STEM concepts, processes, or careers

- Skills based on STEM concepts or processes

- Behavior related to STEM concepts, processes, or careers

A second document, Learning Science in Informal Environments: People, Places, and Pursuits (National Research Council 2009), focuses on characterizing the cognitive, affective, social, and developmental aspects of science learners. Termed the "LSIE strands," these aspects of science participation include:

- Interest and motivation to learn about the natural world

- Application and understanding of science concepts

- Acquisition of skills related to the practice of science

- Reflecting on science as a way of knowing, participating in, and communicating about science

- Identifying oneself as someone capable of knowing, using, and contributing to science

The authors of the LSIE strands noted that while the concepts originated in research, at the time of writing they had not yet been applied or analyzed in any systematic venue. The significant overlap between the LSIE strands and the ISE Framework's impact categories is shown in Table 1.

A third ISE document also contributed to framing this study. In 2009, an inquiry group sponsored by the Center for Advancement of Informal Science Education (CAISE) produced "Public Participation in Scientific Research: Defining the Field and Assessing Its Potential for Informal Science Education" (Bonney et al. 2009a), which was created as a "first step toward developing an organized methodology for comparing outcomes across a variety of Public Participation in Scientific Research (PPSR) projects" (p.20). This paper included a rubric of potential citizen science learning outcomes, based on the ISE Framework, and examined ten NSF-funded citizen science projects to assess whether they reported outcomes similar to those described in the ISE Framework. 
Table 1: Comparison of NSF Framework and LSIE strands.

\section{NSF Framework Category}

Knowledge, Awareness, Understanding: Measurable demonstration of assessment of, change in, or exercise of awareness, knowledge, understanding of a particular scientific topic, concept, phenomena, theory, or careers central to the project.

Engagement, interest or motivation in science: Measurable demonstration of assessment of, change in, or exercise of engagement/interest in a particular scientific topic, concept, phenomena, theory, or careers central to the project.

Skills related to science inquiry: Measurable demonstration of the development and/or reinforcement of skills, either entirely new ones or the reinforcement, even practice, of developing skills.

Attitudes toward science: Measurable demonstration of assessment of, change in, or exercise of attitude toward a particular scientific topic, concept, phenomena, theory, or careers central to the project or one's capabilities relative to these areas. Attitudes refer to changes in relatively stable, more intractable constructs such as empathy for animals and their habitats, appreciation for the role of scientists in society or attitudes toward stem cell research.

Behavior: Measurable demonstration of assessment of, change in, or exercise of behavior related to a STEM topic. Behavioral impacts are particularly relevant to projects that are environmental in nature since action is a desired outcome.

\section{LSIE Strands}

Strand (2), Understanding: Come to generate, understand remember, and use concepts, explanations, arguments, models, and facts related to science.

Strand (1), Interest and motivation: Experience excitement, interest and motivation to learn about phenomena in the natural and physical world.

Strand (3), Science Exploration: Manipulate, test, explore, predict, question, and make sense of the natural and physical world; and Strand (5): Participate in scientific activities and learning practices with others, using scientific language and tools

Related to Strand (6), Identity: Think about themselves as science learners, and develop an identity as someone who knows about, uses, and sometimes contributes to science. Also, related to Strand (4), Reflection: Reflect on science as a way of knowing; on processes, concepts, and institutions of science; and on their own process of learning about phenomena.

Related to Strand (5), Skills: Participate in scientific activities and learning practices with others, using scientific language and tools.
One result of the CAISE report was a realization that citizen science practitioners were measuring project outcomes in varied ways, making it difficult for crossprogrammatic research to study the collective impact of the field. Another result was the development of a project typology based on the level of participant involvement in the scientific process (Bonney et al. 2009a). This typology described "Contributory" projects that are researcherdriven, where participants primarily focus on data collection; "Collaborative" projects that are typically led by researchers, but may include input from participants in phases of the scientific process such as designing methods, analyzing data, and disseminating results; and "Co-created" projects that involve participants in all aspects of the scientific process, from defining a question to interpreting data to disseminating results (Figure $\mathbf{1}$ ). This typology allowed projects designed for different reasons and in different ways to be grouped to help researchers understand common outcomes.

The three documents described above served as foundations for articulating learning outcomes from citizen science participation, however, they lacked systematic empirical support. This study provides such support by ground truthing and applying the concepts within the ISE Framework, the LSIE strands, and the Bonney et al. (2009a) rubric to the field of citizen science.

\section{Methods and Results}

Our research used two sources of data-a structured review of citizen science project websites and an online survey of citizen science practitioners-to address the following three questions:
1) What are the learning outcomes that are intended or desired by citizen science practitioners, and to what extent do these outcomes align with those described by the field of informal science education? (Data Source: Website Review)

2) What is the status of evaluation of citizen science learning outcomes across the field? (Data Source: Online practitioner survey)

3) How are citizen science learning outcomes measured by different projects? (Data Source: Online practitioner survey)

We also conducted a literature review to uncover definitions, descriptions, and elucidations of the learning outcomes that we identified through our research. We used the results of this review, along with our new understanding of the outcomes desired and measured by citizen science practitioners, to develop a framework of common learning outcomes for the citizen science field.

\section{Intended Learning Outcomes}

To describe and understand the learning outcomes that are intended or desired by citizen science practitioners as they develop projects, we first identified individual projects by conducting a semi-structured search of the following citizen science portals: Citizen Science Central (citizenscience.org); InformalScience (informalscience. org); SciStarter (scistarter.com); Citizen Science Alliance (citizensciencealliance.org); and National Directory of Volunteer Monitoring Programs (yosemite.epa.gov/ water/volmon.nsf/). The last portal included 800 projects, from which we sampled every fifth one. If a project 
was listed on multiple portals, we included it only once. In total, 327 citizen science projects met our criteria for study inclusion: Being open to participation in the U.S. or Canada, having an online presence, and being operational at the time of the search (2011). The complete list of databases and search terms used to locate citizen science projects is available in the supplemental material for this paper (Appendix A).

From each of the 327 project websites, we gathered the following information: Project name, URL, contact information, general goal statements, learning objectives or desired outcomes (if any), and potential indicators of learning (if any). Nine percent of project websites did not describe intended learning outcomes (e.g., some projects stated their goals to be purely scientific in nature), but the remaining $92 \%$ of projects described at least one. We coded each goal statement and learning objective into one of the major categories outlined in the ISE Framework (knowledge, engagement, skills, attitude, behavior, other) and into sub-codes outlined in the assessment rubric by Bonney et al. (2009a).

Several projects described multiple learning outcomes. In these cases, each distinct outcome was coded separately. For example, the Great Lakes Worm Watch states that its goal is "increasing scientific literacy and public understanding of the role of exotic species in ecosystems change." Objectives are to "provide the tools and resources for citizens to actively contribute to the development of a database documenting the distributions of exotic earthworms and their impacts across the region as well as training and resources for educators to help build understanding of the methods and results of scientific research about exotic earthworms and forest ecosystems ecology." The text from the goal statement and learning objectives (left) were coded into the outcomes categories on the right:
- Increasing scientific literacy $\rightarrow$ content knowledge and public understanding
- Citizens actively contribute data collection and to the development of a $\rightarrow$ monitoring, data database submission

- Help build understanding of Nature of Science the methods and results of $\rightarrow$ knowledge scientific research

Results from our coding of project goals and objectives are presented in Table $\mathbf{2}$. They reveal that the number of aspirational learning outcomes for projects ranged from zero to as many as seven, with about $40 \%$ of projects including at least two. The majority of projects (59\%) focus on influencing skills related to data collection and monitoring. Intended outcomes for these projects are often stated as "Volunteers gain data collection and reporting skills." The second most frequently stated intended learning outcome ( $28 \%$ of projects) was understanding of content knowledge (e.g., "volunteers learn about macroinvertebrates and stream health"). The third most-common intended outcome, increased environmental stewardship-which typically includes some type of behavior change (e.g., "engage watershed residents in protecting water quality")-was specified by about $26 \%$ of projects. Other intended learning outcomes were mentioned much less frequently,

Table 2: Count of specified learning outcomes as coded from 327 citizen-science project websites. Percentages represent the proportion of projects that described the stated outcome. Several projects stated more than one outcome.

\begin{tabular}{lrr}
$\begin{array}{l}\text { Stated Outcomes on project } \\
\text { websites }\end{array}$ & $\begin{array}{c}\text { Count of projects } \\
\text { stating outcome } \\
(\mathbf{N = 3 2 7 )}\end{array}$ & $\begin{array}{c}\text { Percentage of } \\
\text { projects stating } \\
\text { outcome }\end{array}$ \\
\hline Data Collection and Monitoring & 193 & $59 \%$ \\
Content Knowledge & 90 & $28 \%$ \\
Environmental Stewardship & 86 & $26 \%$ \\
No Education Goal Specified & 29 & $9 \%$ \\
Attitude/Awareness & 25 & $8 \%$ \\
Nature of Science & 20 & $6 \%$ \\
Data Analysis & 14 & $4 \%$ \\
Interest in the Environment & 13 & $4 \%$ \\
Civic Action & 12 & $4 \%$ \\
Submitting Data & 12 & $4 \%$ \\
Interest in Science & 10 & $3 \%$ \\
Community Health & 9 & $3 \%$ \\
Communication Skills & 7 & $2 \%$ \\
Using Technology & 6 & $2 \%$ \\
Science Careers & 4 & $1 \%$ \\
Designing Studies & 2 & $5 \%$
\end{tabular}


including increases in knowledge of the nature of science, data analysis skills, interest in the environment, civic action, data submission, communication skills, use of technology, science careers, study design, and also shifts in attitude/awareness. Considering all projects for which intended learning outcomes were stated, each of the ISE Framework impact categories was represented, suggesting a strong alignment between learning outcomes desired for citizen science participants and those for participants in the informal science learning community more generally.

\section{Status of Citizen Science Project Evaluation}

To uncover the status of evaluation of citizen science learning outcomes across the field, we conducted an online survey of citizen science practitioners in March 2011. Delivered via Survey Monkey ${ }^{\mathrm{TM}}$, the survey contained 25 questions, including 20 closed-ended questions with predetermined options including "other." The remaining five questions were open-ended, providing text boxes for answers. Only one question, which asked respondents to classify their project according to the three-model typology of citizen science developed by Bonney et al. (2009a), required a response. Additional questions focused on the duration of the project, the approximate number of participants, and the type of training that participants received. Respondents also were asked if any type of evaluation had ever been conducted for their project; details about evaluations that were conducted; what learning outcomes described in the ISE Framework had been measured; and what other types of outcomes had been measured. The complete set of survey questions is available in the supplemental material (Appendix B).

Following approval by the Cornell University Institutional Review Board (\#1102002014), we sent an email invitation to potential respondents describing the goal of the survey and explaining that participation was voluntary and confidential. Two reminder emails were sent approximately two and four weeks following the initial invitation. An informed consent statement was included at the start of the survey. Potential respondents were recruited via the citizenscience.org listserv (citsci-discussion-l), which anyone could join, and which at the time of recruitment had approximately 1,100 members. Not all members of the listserv were project leaders, and multiple list members likely represented a single project, making it difficult to know the actual number of projects represented by listserv members. After the survey was closed, we made sure that all responding projects were included in the previously described website review, to obtain as much overlap between the two datasets as possible.

The survey was completed by 199 respondents representing 157 unique projects (some projects had multiple entries, in which case only the first entry was included; other respondents failed to include information about their project name, which was optional). All but ten of the 157 unique projects also were represented in the project website data. The remaining ten projects that responded to the online survey but were not in the website review were either no longer operational, not in the US or Canada, or did not have a web presence. The majority of projects (72 or $37 \%$ ) had been operating from $1-5$ years, and nearly half $(49 \%)$ had fewer than 100 participants. Because most questions were optional, response rates varied for different survey items.

Results revealed that of the 199 respondents, 114 or $57 \%$ had undertaken some type of project evaluation. More than half of the evaluations were administered by internal project staff to measure project outcomes or impacts, mostly using data collected through surveys. About one third of respondents reported conducting post-only or pre-and posttest evaluation designs. Reasons for conducting project evaluations included: Gauging participant learning; identifying project strengths and weaknesses; obtaining additional funding or support; promoting a project more broadly; and providing recommendations for project improvement. In addition to asking about project learning outcomes (described in the next section), the survey also asked what other aspects of the project had been evaluated. Two thirds of participants reported measuring satisfaction or enjoyment with the project, followed by motivation to participate (53\%) and evaluation of project outputs such as numbers of participants, web hits, journal articles, and amount of data collected (44\%). Other measured outcomes included scientific/conservation (39\%); effectiveness of workshops and trainings (38\%); data quality (37\%); community capacity building (23\%); and social policy change (3\%).

Another open-ended question asked respondents "Please do your best to provide the name or description of any instrument (e.g., Views on Science and Technology Survey) used to collect evaluation data, even if you developed the instrument." Of the 72 respondents to this question, only three had used a pre-existing, validated instrument. The majority of respondents had developed their own instruments in-house or had an external evaluator develop original instruments. A handful of respondents replied with "Survey Monkey" or some other data collection platform as opposed to describing an evaluation instrument. Some mentioned tools such as GPS units or calipers as instruments used by the project, while others stated that they did not understand the question. When asked about their overall satisfaction with their evaluations, more than half of respondents expressed agreement or strong agreement that evaluations were of high quality, that evaluation findings were informative to the project developers, that recommendations from the evaluation were implemented, that the project had improved as a result of evaluation, that they learned a lot about evaluation, and that they felt confident they could personally conduct an evaluation in the future.

Survey respondents also were asked about aspects of the evaluation process for which they would like assistance. The highest priority was help with developing goals, objectives, and indicators, followed by creating or finding appropriate survey instruments, help with analyzing or interpreting data, and help with data collection. Participants also were asked what specific resources would be most helpful for conducting evaluations. The most common replies were a database of potential surveys and data collection instruments; sample evaluation reports from citizen science; examples of evaluation designs; and an entry-level guide for conducting evaluations. 
Finally, respondents were presented with a list of eight different online organizations that support or provide resources for evaluation and were asked how often they access them. Surprisingly, the majority of respondents had never heard of any of the resources or organizations. The only exception was citizenscience.org, which was used by $46 \%$ of respondents, but rarely (as opposed to frequently, sometimes, or never). These results show a range of evaluation efforts and a positive attitude toward evaluation and findings among citizen science practitioners, but also a need for more knowledge of and accessibility to evaluation tools and resources.

\section{Measurement of Learning Outcomes}

Respondents who reported having conducted evaluations (114 or $57 \%$ ) were asked "For the most recent evaluation of your project, which broad categories of learning outcomes, if any, were evaluated?" Responses to this question were based on the ISE Framework broad impact categories. Aggregated results across all projects revealed that interest or engagement in science was the most commonly measured outcome (46\%), followed by knowledge of science content $(43 \%)$. Behavior change resulting from participation and attitudes toward science process, content, careers, and the environment accounted for 36\% and 33\%, respectively, of measured learning outcomes. Science inquiry skills (e.g., asking questions, designing studies, data collection, data analysis, and using technology) were the least commonly measured outcomes across all projects $(28 \%)$. In an open-ended question about other types of learning outcomes, about $10 \%$ of respondents also described measuring motivation and self-efficacy or confidence to participate in science and environmental activities.

Considering differences in categories of learning outcomes measured within project types, contributory projects (for which there were 69 respondents that had conducted evaluations) reported measuring interest in science most frequently $(43 \%)$ and skills of science inquiry least frequently (18\%). Two-thirds of all collaborative projects $(\mathrm{N}=21)$ measured content knowledge, followed by interest (57\%), behavior change (52\%), and attitudes and skills (both 43\%). Only nine survey respondents represented co-created projects that had conducted evaluations, and of these, skills of science inquiry were measured most often. Responses combined across projects and separated among project types are summarized in Figure 2.

Earlier in this paper we showed that a majority of citizen science project websites described intended learning outcomes very similar to those in the ISE framework, although not always using the same language. Results from the online practitioner survey added to our "ground truthing" of the ISE Framework, as respondents described attempts to measure these same outcomes, albeit to varying degrees. Open-ended responses highlighted the need to emphasize efficacy as an important learning outcome in citizen science. Survey respondents also made it clear that additional resources were needed to help formulate and measure learning outcomes.

\section{A Framework for Articulating and Measuring Common Learning Outcomes for Citizen Science} In addition to synthesizing and comparing empirical results from our website review and practitioner survey to describe intended and measured learning outcomes, we used key word searches to conduct a review of more than 40 peer-reviewed articles focused on defining and measuring these learning outcomes. Our data and review facilitated a re-conceptualization or contextualization of several of the impact categories presented in the ISE Framework to make them relevant to citizen science, in

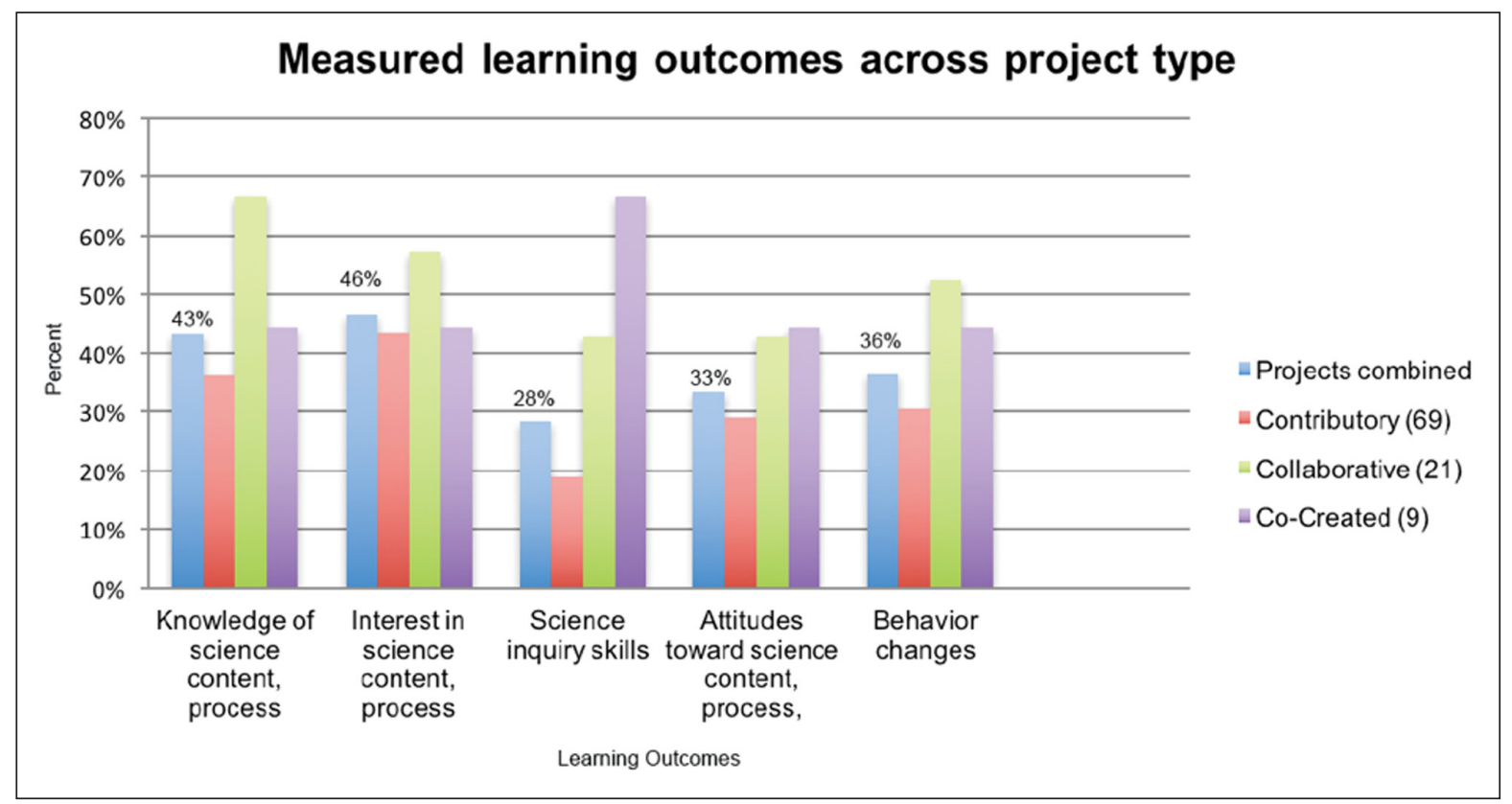

Figure 2: Measured learning outcomes from online survey of citizen science practitioners who reported having conducted some sort of evaluation $(n=99)$. 
particular environmentally based projects. For example, some outcomes uncovered in our research, such as "skills of science inquiry," map well to the categories and their definitions in the ISE framework. Other outcomes, such as "attitude," required clarification. Our new framework is thus based on both empirical data and contributions from the literature and includes the following learning outcomes: Interest in Science and the Environment; Selfefficacy for Science and the Environment; Motivation for Science and the Environment; Knowledge of the Nature of Science; Skills of Science Inquiry; and Behavior and Stewardship (Figure 3).

This framework should help citizen science practitioners consider some of the more commonly desired and achievable learning outcomes when designing projects. However, we emphasize that no single project should try to achieve and/or measure all, or even most, of these outcomes, as doing so can set up unreasonable expectations for both the project and its evaluation. We also note that the framework is not exhaustive. Indeed, as citizen science continues to expand, new research will inevitably reveal other learning outcomes that are important to articulate and measure.

Below we describe each outcome within the framework, highlighting how each has been explained in the broad educational field and also providing examples of how each has been used in published studies of citizen science. These outcomes are not hierarchical but, beginning with interest in science and the environment, build from and reinforce each other.

\section{Interest in Science and the Environment}

We define interest as the degree to which an individual assigns personal relevance to a science or environmental topic or endeavor. Within ISE, Hidi and Renninger (2006) treat interest as a multi-faceted construct encompassing cognitive (thinking), affective (feeling), and behavioral (doing) domains across four phases of adoption: triggered situational interest typically stimulated by a particular event and requiring support by others; maintained situational interest, which is sustained through personally meaningful activities and experiences; emerging individual interest characterized by positive feelings and self-directed pursuit of re-engaging with certain activities; and well-developed individual interest leading to enduring participation and application of knowledge. Our definition of interest is compatible with Hidi and Renninger's (2006) later phases of interest development, which are characterized by positive feelings and an increasing investment in learning more about a particular topic. Interest in science is considered a key driver to pursuing science careers in youth (Maltese and Tai 2010; Tai et al. 2006) and sustained lifelong learning and engagement in adults (Falk et al. 2007; Hidi and Renninger 2006). Over time, this type of interest can lead to sustained engagement and motivation and can support identity development as a science learner (Fenichel and Schweingruber 2010; National Research Council 2009). Further, interest is noted as an important precursor to deeper engagement in democratic decision-making processes regarding science and technology (Mejlgaard and Stares 2010).

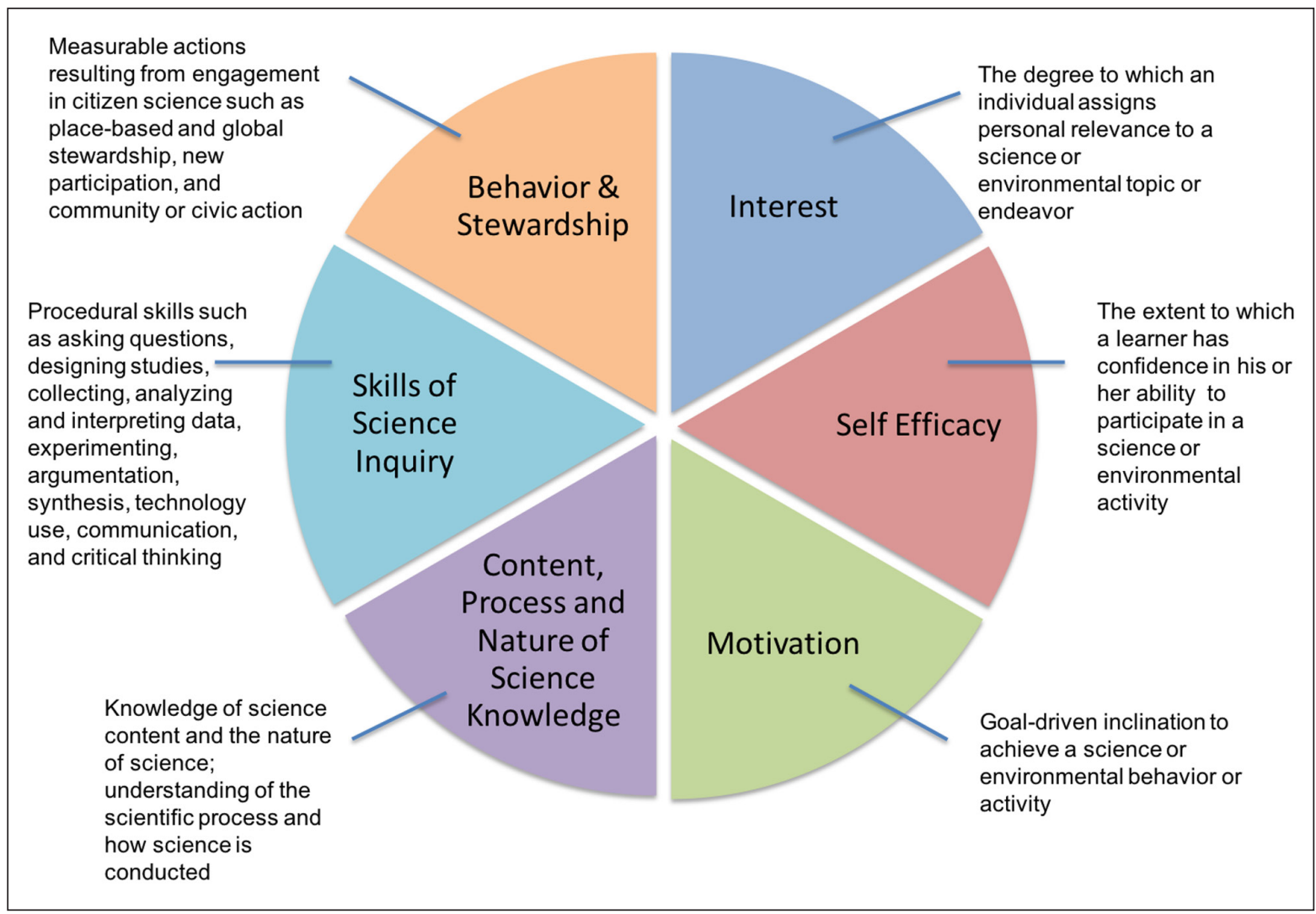

Figure 3: Framework for Articulating and Measuring Individual Learning Outcomes from Participation in Citizen Science. 
Although interest is considered to be an attitudinal structure (see Bauer et al. 2000; Fenichel and Schweingruber 2010; Sturgis and Allum 2004), equating interest with attitudes should be avoided because attitude is a very broad construct, encompassing related but distinct sub-constructs such as efficacy, interest, curiosity, appreciation, enjoyment, beliefs, values, perseverance, motivation, engagement, and identity (Osborne et al. 2003). Interest also has been used synonymously with engagement (Friedman et al. 2008), but as McCallie et al. (2009) point out, engagement has yet to be well defined and has multiple meanings within the literature, particularly in ISE.

Citizen science projects, especially those for which repeated visits or experiences are the norm, can lend themselves to deeper and sustained interest in science and the environment, yet few studies have looked at interest as an outcome, and those that have find mixed results. Price and Lee (2013) reported increased interest in science among Citizen Sky observers, especially among participants who engaged in online social activities. Crall et al. (2012) examined general interest in science as a reason for participation in citizen science and suggested that interest was not a driving force for joining a project. Interest in specific nature-based topics, i.e., butterflies, was seen as a driver for engagement and also as a motivator for adding increasingly more complex data protocols to the French Garden Butterflies Watch project (Cosquer et al. 2012). Other research has shown that interest in use of natural resources can be a very strong determinant for future and sustained involvement in the decision-making process about management of natural resources (Danielsen et al. 2009). From these studies, it appears that examining interest in science more broadly may be less effective than measuring specific science topics. However, an audience's pre-existing interests in specific topics may not change significantly through participation.

\section{Self-efficacy for Science and the Environment}

Another important outcome for studying learning is self-efficacy, i.e., a person's beliefs about his/her capabilities to learn specific content and to perform particular behaviors (Bandura 1997). Research has found that self-efficacy affects an individual's choice, effort, and persistence in activities (Bandura 1982, 2000; Schunk 1991). Individuals who feel efficacious put more effort into their activities and persist at them longer than those who doubt their abilities. Self-efficacy is sometimes referred to as "perceived competence" (in Self Determination Theory) and "perceived behavioral control" (in Ajzen's Theory of Planned Behavior, Ajzen 1991). Berkowitz et al. (2005) treat self-efficacy as an essential component in environmental citizenship (along with motivation and awareness), which is dependent on an individual's belief that they have sufficient skills, knowledge, and opportunity to bring about positive change in their personal lives or community.

In the context of citizen science, self-efficacy is the extent to which a learner has confidence in his or her ability to participate in a science or environmental activity. In a study involving classrooms, middle school students participating in a horseshoe crab citizen science project showed greater gains in self-efficacy than a control group (Hiller 2012). In an online astronomy project, however, researchers found a significant decrease in efficacy toward science, possibly owing to a heightened awareness of how much participants did not know about the topic (Price and Lee 2013). Crall et al. (2011) determined that selfefficacy is not only important in carrying out the principal activities of a project but also in the potential for individuals to carry out future activities related to environmental stewardship. Working in a participatory action project with Salal harvesters, Ballard and Belsky (2010) found that the process of co-developing and implementing different experiments increased workers' self efficacy regarding their skills in scientific research. Although efficacy was not called out directly in the ISE Framework, it can be considered part of the LSIE Strand 6, "identity as a learner" (National Research Council 2009). Self-efficacy also was mentioned by project leaders in our online survey and thus appears to be an important potential outcome from citizen science participation.

\section{Motivation for Science and the Environment}

Motivation is a multi-faceted and complex attitudinal construct that describes some form of goal setting to achieve a behavior or end result. The LSIE strands (National Research Council 2009) include motivation to sustain science learning over an individual's lifetime as an important aspect of learning in informal environments. The literature on volunteerism frames motivation as an important factor in effective recruitment, accurate placement, and volunteer satisfaction and retention (Clary and Snyder 1999, Esmond et al. 2004). Of the dozens of theories on motivation, two perspectives seem especially relevant to volunteerism and citizen science. First, the Volunteer Functions Inventory (VFI), developed by Clary et al. (1998), examines how behaviors help individuals achieve personal and social goals. Clary et al.'s (1998) categories of motivation include values (importance of helping others); understanding (activities that fulfill a desire to learn); social (influence by significant others); career (exploring job opportunities or work advancement); esteem (improving personal self-esteem); and protective (escaping from negative feelings). Wright et al. (2015) studied the motivations of birders in South Africa using a modified version of the VFI and found five categories of motivation to be most important: Recreation/nature; values; personal growth; social interactions; and project organization.

The second perspective comes from Self-Determination Theory (SDT), which treats motivation as an explanatory variable for meeting basic psychological needs (i.e., competency, relatedness, and autonomy) and describes different types of motivations as falling on a continuum from intrinsic to extrinsic (Ryan and Deci 2000a, 2000b). According to SDT, individuals are likely to continue pursuing a goal to the extent that they perceive intrinsic value in the pursuit of that goal (i.e., the extent to which they experience satisfaction in performing associated behaviors themselves versus performing behaviors to comply with extrinsic goals such as conforming to social pressures, fear, or receiving rewards). Although SDT can 
help practitioners better understand the psychological needs behind participation, few published studies have used SDT in the context of citizen science. One exception is a paper by Nov et al. (2014), which used SDT with social movement participation models in an examination of three digital citizen science projects. These researchers found that intrinsic motivation was one of four drivers that influenced quantity of participation, but that it did not affect quality of participation.

In the context of citizen science, motivation can serve as both an input and outcome, i.e., to understand the basis of motivation for ISE/citizen science experiences (input) and to sustain motivation to continue participating over long time periods (outcome). However, most studies have examined reasons for participation such as the desire to contribute (see Bell et al. 2008; Hobbs and White 2012; McCaffrey 2005; Raddick et al. 2010; Reed et al. 2013), rather than motivations, which describe the psychological underpinnings of behavior (e.g., "because it makes me feel good"). In an examination of motivation in online projects, Rotman et al. (2012) described a complex and changing framework for motivation that was influenced by participant interest, recognition, and attribution. Although several studies have purported to examine motivation, it has not been defined nor studied uniformly throughout the field of citizen science. Nevertheless, the major consensus appears to be that motivation for citizen science, like other volunteer activities, is dynamic and complex.

\section{Content, Process, and Nature of Science Knowledge}

Included within the ISE Framework's impact category of "awareness, knowledge, and understanding" are several subcategories such as knowledge and understanding of science content; knowledge and understanding of science processes; and knowledge of the Nature of Science. Knowledge of science content refers to understanding of subject matter, i.e., facts or concepts. Knowledge of the process of science refers to understanding the methodologies that scientists use to conduct research (for example, the hypothetico-deductive model or "scientific method"). Knowledge of the Nature of Science (NOS) refers to understanding the epistemological underpinnings of scientific knowledge and how it is generated, sometimes presented from a postpositivist perspective (Lederman 1992). NOS addresses tenets of science such as tentativeness; empiricism; subjectivity; creativity; social/cultural influence; observations and inferences; and theories and laws (see Lederman 1992, 1999, Lederman et al. 2001, 2002). For improving scientific literacy, understanding of NOS and the process of science are generally considered more important than understanding basic content or subject matter (American Association for the Advancement of Sciences 1993; National Research Council 1996; NGSS 2013), and knowledge of the process of science is a regular component of well-established assessments of science knowledge (National Science Board 2014). Despite this recognition, most attempts to measure science literacy within the ISE field fall back on content knowledge, i.e., rote memorization of facts, rather than knowledge of the nature or process of science (Bauer et al. 2000; Shamos 1995).
Indeed, citizen science evaluations have typically emphasized measuring gains in topical content knowledge as opposed to science process knowledge, with mixed results (Ballard and Huntsinger 2006; Bonney 2004; Braschler et al. 2010; Brewer 2002; Devictor et al. 2010; Evans et al. 2005; Fernandez-Gimenez et al. 2008; Jordan et al. 2011; Kountoupes and Oberhauser 2008; Krasny and Bonney 2005; Phillips et al. 2006; Sickler et al. 2014; Trumbull et al. 2000; Trumbull et al. 2005). Overdevest et al. (2004) did not find a significant increase in project participant knowledge about streams and water quality, probably because new volunteers were already highly knowledgeable about the subject matter. Price and Lee (2013) actually found a decrease in science content knowledge among project participants, likely owing to exaggerated notions of participants' self-perceived content knowledge before starting the project and the realization of how much they did not know after participating in the project.

However, a few studies have used measures of the process of science to assess impacts of citizen science project participation. Jordan et al. (2011) and Brossard et al. (2005) used adaptations of the science and engineering indicators and showed no gains in understanding of the process of science as a result of citizen science participation. In contrast, Ballard et al. (2008) used interview data to show evidence that the Salal harvesting project "... increased local people's understanding of the scientific process and of the ecosystem on which they were a part (p. 14)". And significant increases in understanding of the process of science before and after participation in a stream water quality-monitoring project were reported by Cronin and Messemer (2013). However, this study had a very small sample size, which may limit generalizability of the results.

Likewise, few citizen science projects have attempted to study understanding of the NOS. Jordan et al. (2011) found no evidence for change in knowledge of the NOS using pre-post scenario-based questions in an invasive species project. Price and Lee (2013) found little evidence that project participation influenced epistemological beliefs about NOS, owing to the fact that "epistemological beliefs are personal beliefs and thus harder to change after participating in only one citizen science project" (p. 793). These findings suggest that while citizen science can effectively demonstrate gains in content knowledge, it has a long way to go before it can positively establish increases in understanding of science process and the NOS.

\section{Skills of Science Inquiry}

Skills of science inquiry are observable practices that can be transferred to daily life, such as asking and answering questions; collecting data; developing and using models; planning and carrying out investigations; reasoning about, analyzing, and interpreting data; constructing explanations; communicating information; and using evidence in argumentation (National Academies of Science, Engineering, and Medicine 2016; NGSS Lead States 2013).

The hands-on nature of many environmentally based citizen science projects makes them particularly well suited to influence the development and/or 
reinforcement of certain science-inquiry skills including asking questions; designing studies; collecting, analyzing, and interpreting data; and discussing and disseminating results (Bonney et al. 2009a; Jordan et al. 2012; Phillips et al. 2012; Trautmann et al. 2012). Top priorities for many practitioners are helping participants learn to follow protocols and exercise accurate data collection skills, because these practices directly influence data quality. The fieldwide emphasis on data quality likely comes from the large percentage of contributory, scientist-driven projects, for which a key goal is gathering data of sufficient quality to add to the existing knowledge base through publication in peer-reviewed journals. Consequently, many citizen science projects most effectively influence skills that are related to data and sample/specimen collection, identification of organisms, instrument use, and sampling techniques. Many projects also engage participants in the use of various technological tools such as GPS units, digital thermometers, water conductivity instruments, rain gauges, nets, and smartphones, to name just a few (Figure 4).

A few researchers have begun to study skill acquisition in citizen science. Becker et al. (2013) showed an increase in the ability to estimate noise levels with increasing participation in WideNoise, a soundscape project operated through mobile devices. Increases in youths' self-reported science inquiry skills, such as their perceived ability to identify pond organisms and to develop testable hypotheses before and after participation in Driven to Discover, also have been reported (Meyer et al. 2014). Sullivan et al. (2009) describe the use of communication prompts and strategies to "steer birders toward providing more useful data" and essentially change the birding habits of eBird participants to increase data quality. Using the theory of legitimate peripheral participation, Mugar et al. (2014) used practice proxies, a form of virtual and trace ethnography, to increase accuracy of data annotation among new members. Additionally, some projects have successfully conducted small-scale studies that compare volunteer-collected data to those collected by experts, thereby creating a baseline metric for assessing their participants' skills (see Crall et al. 2011; Jordan et al. 2011; Schmeller et al. 2009).

Another hallmark of citizen science is the collection of large, publicly available data sets and rich, interactive data visualizations. Many projects that provide data visualizations may seek to enhance skills related to data interpretation, i.e., the ability to effectively comprehend information and meaning, often presented in graphical form (Devictor et al. 2010). In one of the few studies examining data interpretation in citizen science, Thompson and Bonney (2007) showed that even the majority of "active users" of eBird did not properly use the extensive array of data-analysis tools. Numerous studies in educational research have shown that assessing the type of reasoning skills needed for data interpretation requires asking a series of reflective questions to determine one's justification underlying the reasoning (e.g., Ayala et al. 2002; Roth and Roychoudhury 1993).

Other inquiry skills such as study design, communication, critical thinking, decision making skills, and critically evaluating results are less studied within the citizen science literature. Crall et al. (2012) used open-ended questions to determine whether engaging in an invasive species project improved the abilities of participants to explain a scientific study, write a valid research question, and provide a valid sampling design. These researchers noted positive gains in all but the ability to explain a scientific study. Char et al. (2014) found an increase from pre-post training in the ability of COASST volunteers to correctly weigh evidence to determine whether it contained sufficient information for accurately identifying species. These few studies show the potential for studying citizen science participants to evaluate the development of complex science inquiry skills, but such studies are in their infancy.

\section{Behavior and Stewardship}

Behavior change and development of environmental stewardship are among the most sought-after outcomes in science and environmental education programs, both in and out of schools (Bodzin 2008; Heimlich et al. 2008; Kollmuss and Agyeman 2002; Stern 2000; Stern et al. 2008; Vining et al. 2002). Theories examining various determinants of environmental behavior include those espousing the links between knowledge, attitude, and behavior (Hungerford and Volk 1990; Kollmuss and Agyeman 2002; Osbaldiston and Schott 2012; Schultz 2011); attitudes and values (Ajzen 1985; Fishbein and Ajzen 1975); behavior modification and intervention (De Young 1993); and nature exposure (Kaplan 1995; Kellert and Wilson 1993; Ulrich 1993; Wilson 1984).

We define behavior and stewardship as measurable actions resulting from engagement in citizen science, but external to the protocol activities and the specific projectbased skills of the citizen science project. For example, collecting water quality data may be a new behavior for a project participant, but if the data collection is part of the project protocol it should be measured as a new skill rather than a new behavior. However, somebody decreasing their water usage as a result of participating in a water quality monitoring project would be an example of behavior change. Our literature review identified five categories of behavior and stewardship that are of interest to the citizen science field and for which we provide definitions below: Global stewardship behaviors; place-based behaviors; new participation; community or civic action; and transformative lifestyle changes.

Global stewardship refers to deliberate changes in behavior that minimize someone's individual ecological footprint and which collectively can have global influence (e.g., installing low-flow shower heads, recycling, purchasing energy-efficient appliances). Place-based behaviors refer to observable actions to directly maintain, restore, improve, or educate about the health of an ecosystem beyond the activities of a citizen science project (e.g., removing invasive species; cleaning up trash; eliminating pesticide use; purchasing locally grown food; engaging in outreach to youth groups). New participation is defined as engagement in science or environmental activities, organizations, or projects spurred on by participation in 
a citizen science project. Community or civic action refers to participation in civic, governmental, or cultural affairs to solve problems at the local, regional, or national level. Actions could include donating to environmental organizations, signing petitions, speaking out against harmful environmental practices, or recruiting others to participate in environmental causes. Finally, transformative lifestyle changes are efforts that require a strong up-front cost or long-term commitment to maintain, such as investing in a hybrid vehicle, becoming a vegetarian, or pledging to use mass transit whenever possible.

Citizen science projects, especially those dealing with environmental topics, are typically hands-on, occur in local environments, and require repeated monitoring and data gathering, making them natural conduits for affecting behavior change (Wells and Lekies 2012). However, research has been limited and results have been mixed regarding the actual influence of citizen science on behavior change. For example, in a study examining two different projects, one on pollinators and one on coyotes, Toomey and Domroese (2013) show that participants engage in new activities and change their gardening practices, but otherwise did not take part in advocacy or change their environmental stewardship practices. Crall et al. (2012) found significant differences between current and planned behavior as a result of participating in an invasive species project using self-reported measures, but the actual behavior change was not well described. Using a case-study approach, Oberhauser and Prysby (2008) claim that participants of the Monarch Larva Monitoring Project "work to preserve habitat at many levels, from advocating a more environmentally friendly mowing regimen and insect-friendly pest control, to challenging parking lot, building, and road development projects

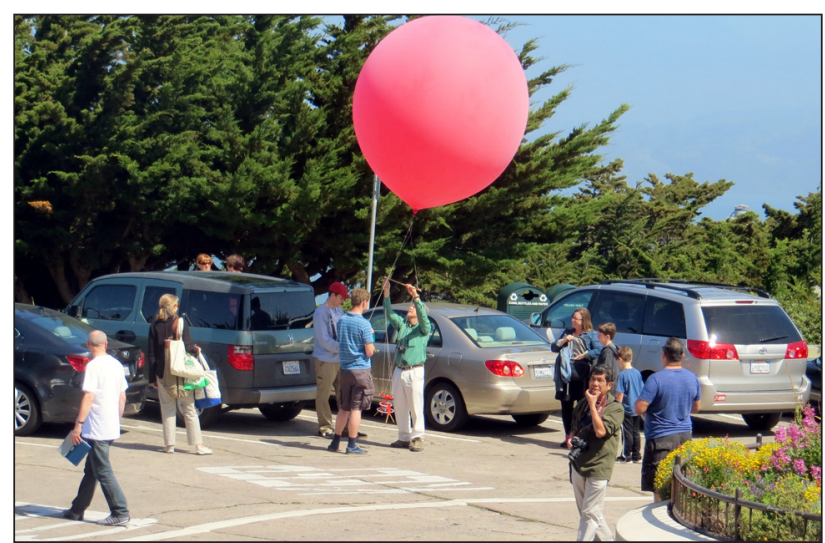

Figure 4: Many citizen science project designers hope not only to collect important scientific information but also to help project participants gain skills such as scientific reasoning. Here, a team of volunteers with Public Lab, a non-profit environmental science community, launch a weather balloon. Data collected via the balloon will be used in 3-D mapping surveys, but figuring out how to measure just what participants are learning as they conduct this research is a challenge for the citizen science field.

Credit: Alan Kotok/Flickr/CC BY-2.0. that threaten monarch habitat (p. 104)." However, the source of these data or accompanying methodologies are not clearly described. Cornwell and Campbell (2012) also used a case study approach and were able to document advocacy and political action by volunteers which directly benefited sea turtle conservation. Evans et al. (2005) documented locally, place-based stewardship in a bird breeding program, while other projects showed no change in place-based stewardship practices (Jordan et al. 2011). In a study of human health effects of industrial hog operations, Wing et al. (2008) describe actions being taken by community groups to engage in decision-making that addresses local environmental injustices. Taken together, these examples provide some evidence that citizen science may influence behavior and stewardship, but more robust methodologies are needed to establish causation. Plenty of anecdotal data also highlight other examples of behavior change that have not been published or exist only in the gray literature.

\section{Discussion}

Results from research conducted through a systematic review of citizen science project websites and a survey of practitioners who design and implement citizen science projects confirm the relevance and applicability of three ISE documents (Friedman et al. 2008; National Research Council 2009; Bonney et al. 2009a) in framing intended learning outcomes for citizen science participants. Informed by this research along with a systematic literature review, we have modified and contextualized these documents to create a new framework that contains definitions and articulations of learning outcomes for the citizen science field. We believe that the framework provides a robust starting point for setting learning goals and objectives for citizen science projects and designing projects to meet those objectives.

Our research has some limitations, however. First, both the co-created and collaborative project categories represented in the online practitioner survey have small sample sizes, so generalizing the types of learning outcomes intended by these project types is challenging. Also, it's unclear whether the distribution across project types in the online survey reflects the actual distribution of contributory, collaborative, and co-created projects across the U.S. and Canada, or if a disproportionate number of contributory projects received and responded to the survey request. We made no additional effort to recruit additional collaborative or co-created project respondents, thus response bias may be an issue. Also, while we made an effort to ensure that projects which responded to the practitioner survey were included in our website review, project level data from the two sources were not examined together. Doing so may have shown convergence or divergence of intended versus measured outcomes, but was beyond the scope of this work and may have violated confidentiality conditions. Finally, this work is a descriptive study based largely on self-reports in the case of the practitioner survey and published desired outcomes in the case of the website review. More robust inferential studies that can examine 
field-wide relationships and causal factors between project characteristics and observed learning outcomes would be a significant next step.

Despite these limitations, our findings provide insights into the ways in which learning has been articulated, studied, and measured by citizen science projects. They also provide information about the status of citizen science project evaluation in general. For example, an overwhelming majority of survey respondents expressed positive attitudes toward the importance of evaluation and the evaluation process. However, they also expressed a need for additional support and resources to conduct evaluations. Nearly all respondents reported developing their own evaluation instruments, although most projects measured very similar outcomes. And the fact that very few projects were aware of resources available for guidance in conducting evaluations and locating evaluation instruments suggests that work needs to be done to disseminate tools and resources to the citizen science professional community.

The comparison of intended learning outcomes described on citizen science project websites and the outcomes actually measured by projects highlights some interesting disconnects. For example, fewer than 5\% of project websites stated "increasing interest in science and/or the environment" as an intended outcome, yet interest in science was the most commonly measured outcome $(46 \%)$ across all projects in the online survey. The frequent measurement of interest in science may result from the relative ease of obtaining instruments to measure this outcome or it may be a proxy for measuring interest in the specific topic addressed by the project (e.g., birds, butterflies, astronomy, weather). Further, despite these reported measurements, few studies have published data about changes in interest, perhaps because they have not actually tried to measure it or because the typical citizen science participant (Caucasian, older, highly educated) already demonstrates a high interest in science when joining a project, making it difficult to detect changes in interest over the course of project participation (Brossard et al. 2005; Thompson and Bonney 2007). However, ample opportunity exists for citizen science projects to increase interest in science and the environment by reaching individuals who are not already engaged, especially underserved audiences for whom access to informal science programming may be limited (Bonney et al. 2016; Flagg 2016). Additionally, projects that reach youth audiences via K-12 settings can minimize self-selection bias and carry out quasi-experimental studies to determine whether interest in science is leveraged through citizen science participation (Bonney et al. 2016).

As another example of a disconnect, self-efficacy was seldom stated as an intended outcome in the website review and did not emerge as a major category of desired outcomes via the online survey. However, approximately $10 \%$ of survey respondents mentioned the concepts of "agency," "confidence," or "efficacy" in open-ended comments. As stated earlier, self-perceptions of efficacy affect choices of activities that individuals pursue, how much effort they put toward them, and how long they persist in those pursuits (e.g., Bandura et al. 1977; Weinberg et al. 1979). Enhancing perceptions of efficacy may be the single most important outcome for many citizen science projects, thus we have included efficacy in our framework.

Yet another disconnect relates to motivation. Few project websites mentioned motivation as an intended learning outcome, and our online survey showed that practitioners measured motivation primarily to understand reasons for participation. Motivations change over time, however, and sustaining project participation requires an understanding of changing roles for individuals within a project and motivations for continued participation. More work also is needed to understand how motivations connect to Self-Determination Theory and serve psychological needs within the context of citizen science. For example, the desire to contribute to a project may be associated with a psychological need for competence, and the desire to engage socially with others may serve the psychological need for relatedness. Studies that examine where motivations fall within the intrinsic-extrinsic motivation continuum are needed to understand how motivation might influence sustained participation over time.

Our results also reiterate the inclination for practitioners to expect and measure gains in science content knowledge, typically through context-specific instruments that measure mastery of project activities and program content rather than increased knowledge about the process of science or the Nature of Science. Although some projects have begun to demonstrate outcomes related to "thinking scientifically" (Braschler et al. 2010; Kountoupes and Oberhauser 2008; Trumbull et al. 2000), a gap remains in our understanding of the potential for citizen science to influence deeper understanding of the process of science and the Nature of Science as well as the more complex facets of science inquiry (i.e., critical thinking, reflection, and reasoning). Future work should focus on the development of robust and contextually appropriate tools to better capture deep reflection and rich dialogue about NOS.

In perhaps our most surprising finding, nearly $60 \%$ of project websites in our study listed data collection as an intended outcome, yet across all projects combined, our online survey showed that skills related to data collection were the least-measured outcome (28\%). These findings may reflect the difficulty of measuring attributes such as the acquisition of skills and the relative ease of measuring other constructs such as knowledge, interest, and attitude. This disconnect also represents a potential tension that exists within the citizen science field, particularly among contributory projects: The need for high confidence in data quality versus the dearth of studies that have assessed data collection skills. While several studies demonstrate that volunteers are able to collect data of similar quality to experts, these tend to be isolated examples (Crall et al. 2011; Danielsen et al. 2014). Although a multitude of ways to validate citizen-science data exist (see Kosmala et al. 2016), tools and techniques are needed that can assess changes in participant data collection skills over time.

Additionally, the field needs to better understand whether citizen science participation can influence other important inquiry skills such as the ability to make 
decisions regarding appropriate research methodologies, to use variables and control groups properly, and to evaluate evidence. And as attention is increased on the potential for citizen science to democratize science, further work should examine the extent to which it can support development or reinforcement of critical thinking skills that inform decision making and help to create an informed citizenry. Also, in the new world of "Big Data," citizen science is well poised not only to provide the public with large and robust data sets but also to develop support systems so that users can understand how to effectively use these dynamic resources. Such provisioning may facilitate new lines of research to better understand how participants engage with data sets and what meaning they hold for them.

Finally, in our website review, environmental stewardship was mentioned as an intended outcome by $25 \%$ of projects-second only to data collection-suggesting a strong desire for citizen science projects to influence individual behavior change. About one-third of survey respondents reported measuring behavior change, but based on several open-ended comments, some practitioners equated the act of participating in a project as a change in behavior, meaning that such change was indicated for all participants. Recall, however, that we define behavior change as change that goes beyond project activities. Further, tacit assumptions may exist about engagement in specific project activities leading to more global environmental behaviors (Kollmuss and Agyeman 2002; Vining et al. 2002) (e.g., the assumption that waterquality monitoring can lead to reducing carbon emissions, recycling, and conserving energy). Intended behavioral outcomes should be directly connected to project content and activities, and the knowledge of how to perform these targeted behaviors should be made explicit to participants (Phillips et al. 2012; Toomey and Domroese 2013). While citizen science can likely impact behavior change, the development of effective implementation strategies and measurement of those outcomes are still in their infancy.

\section{Conclusion}

Thousands of citizen science projects exist around the word, reaching potentially millions of people, particularly in the observation and monitoring of species and habitats (Theobald et al. 2015). Such projects have the potential not only to engage individuals in the process of science, but also to encourage them to take positive action on behalf of the environment (Cooper et al. 2007; McKinley et al. 2016). If such outcomes are to be achieved, project developers need to better understand how to design projects so that activities and educational learning opportunities support and align with feasible and realistic outcomes (Shirk et al. 2012).

This study has resulted in a framework to support citizen science practitioners in articulating and measuring learning outcomes for participants in their projects. The framework also should help to build capacity for practitioners seeking to conduct evaluations of citizen science projects by helping them to develop their program theory, i.e., to identify underlying assumptions about how project activities affect expected outcomes (Bickman 2000; Chen 2005; Funnell 2000; Funnell and Rogers 2011). In this regard, most evaluators recommend starting with articulation of project outcomes, then working backward to determine not only what can be achieved and how, but also what can be reasonably measured (Center for the Advancement of Informal Science Education 2011).

Toward that end, work proceeding in parallel to this research is developing generic, yet customizable, evaluation scales that are tested as valid and reliable in citizen science contexts and which align to the framework described above (see DEVISE scales: https://cornell.qualtrics.com/ jfe/form/SV_cGxLGl1AlyAD8FL). By adopting common learning outcomes and measures, the citizen science field can further evaluation capacity and begin to conduct cross-programmatic analyses of citizen science projects to provide funders, stakeholders, and the general public with evidence-based findings about the potential for citizen science to impact the lives of its volunteers. Such studies also could provide critical information regarding why and how to achieve outcomes and under what conditions outcomes can be maximized.

Future work should support continued development of consistent measures that can be used across studies, particularly those that do not rely on self-reports (Becker-Klein et al. 2016; Phillips et al. 2012; Wells and Lekies 2012). Continued professional development opportunities for citizen science practitioners to spearhead evaluations of projects will increase capacity for such endeavors, build a steady source of knowledge about impacts, and lead to improved project design, implementation, and sustainability for the field as a whole. Initiation of in-depth longitudinal studies that measure persistence of change over time would add understanding of the impacts of such experiences (Schneider and Cheslock 2003). To the extent possible, more effort should be placed on studies that include experimental designs, random assignment, and control groups. Such efforts will increase the field's ability to provide evidence for causal connections between citizen science participation and learning outcomes.

Additionally, continued research on learning outcomes should seek to incorporate social learning theories, which may be helpful in understanding how learning happens in citizen science and the mechanisms and processes that enable active learning. Social learning theories such as Cultural Historical Activity Theory (Vygotsky and Cole 1978); Activity Theory (Engeström 1999), Experiential Learning (Dewey 1938; Kolb 1984), Situated Learning Theory (Lave and Wenger 1991), and Communities of Practice (Wenger 1998) are ideally suited for examining learning in citizen science because they emphasize the roles that participation in socially organized activities play in influencing learning (Roth and Lee 2002; National Research Council 2009). Social learning theory may be particularly useful to consider when developing project activities and experiences. Practitioners interested in incorporating social learning theories into citizen science project design, research, and evaluation should refer to the following studies for guidance: Roth and Lee (2004); Brossard et al. (2005); Ballard et al. (2008); Raddick et al. (2009); and Jackson et al. (2014). 
Finally, as citizen science continues to grow, it will be important for the field to take a reflective look at its relative impact, and to evaluate whether appropriate questions are being asked by qualified researchers working across projects that involve diverse audiences and issues. Such an analysis will be a first step in gathering critical evidence to demonstrate the potential of citizen science to truly democratize science.

\section{Additional Files}

The Additional Files for this article can be found as follows:

- Appendix A. Databases and Search terms used to locate citizen science websites. DOI: https://doi. org/10.5334/cstp.126.s1

- Appendix B. Questions from Online Practitioner Survey. DOI: https://doi.org/10.5334/cstp.126.s1

\section{Acknowledgements}

The work described in this paper is part of a larger study called DEVISE (Developing, Validating, and Implementing Situated Evaluation Instruments). DEVISE is based at the Cornell Lab of Ornithology, with Rick Bonney as Principal Investigator and Tina Phillips as Project Director. We thank the project's co-PIs, Kirsten Ellenbogen and Candie Wilderman; project consultants Edward Deci, Cecilia Garibay, Drew Gitomer, Kate Haley Goldman, Joe Heimlich, Chris Niemiec, and Gil Noam; and project advisory board members Heidi Ballard, Rebecca Jordan, Bruce Lewenstein, and Karen Oberhauser. We also thank the many practitioners who took the time to respond to our survey and queries. Finally, we thank many Lab of Ornithology staff who helped along the way including Jennifer Shirk, Matthew Minarchek, Marion Ferguson, and Holly Faulkner. DEVISE is supported by the National Science Foundation under Grant No. 1010744. Any opinions, findings, and conclusions or recommendations expressed in this paper are those of the authors and do not necessarily reflect the views of the National Science Foundation.

\section{Competing Interests}

One of the authors of this paper, Rick Bonney, is editor-inchief of this journal. He was not involved in the process of reviewing the paper other than responding to reviewers' comments.

\section{References}

Ajzen, I. 1985. From intentions to actions: A theory of planned behavior. In: Kuhl, J and Beckmann, J (eds.), Action Control, From Cognition to Behavior. Berlin, Heidelberg: Springer Berlin Heidelberg. DOI: https:// doi.org/10.1007/978-3-642-69746-3_2

Ajzen, I. 1991. The theory of planned behavior. Organizational Behavior and Human Decision Processes, 50(2): 179-211. DOI: https://doi. org/10.1016/0749-5978(91)90020-T

American Association for the Advancement of Science). (ed.) 1993. Benchmarks for science literacy. New York: Oxford University Press.
Ayala, CC, Yin, Y, Shavelson, RJ and Vanides, J. 2002. Investigating the cognitive validity of science performance assessment with think alouds: Technical aspects. Presented at the Annual meeting of the American Educational Researcher Association. New Orleans, LA.

Ballard, HL and Belsky, JM. 2010. Participatory action research and environmental learning: Implications for resilient forests and communities. Environmental Education Research, 16(5-6): 611-627. DOI: https:// doi.org/10.1080/13504622.2010.505440

Ballard, HL, Fernandez-Gimenez, ME and Sturtevant, VE. 2008. Integration of local ecological knowledge and conventional science: A study of seven community-based forestry organizations in the USA. Ecology and Society, 13(2): 37. http://hdl.handle. net/10535/2424.

Ballard, HL and Huntsinger, L. 2006. Salal harvester local ecological knowledge, harvest practices and understory management on the Olympic Peninsula, Washington. Human Ecology, 34(4): 529-547. DOI: https://doi.org/10.1007/s10745-006-9048-7

Bandura, A. 1982. Self-efficacy mechanism in human agency. American Psychologist, 37(2): 122-147. DOI: https://doi.org/10.1037/0003-066X.37.2.122

Bandura, A. 1997. Self-efficacy: The exercise of control. 1st edition New York: Worth Publishers.

Bandura, A. 2000. Exercise of human agency through collective efficacy. Current Directions in Psychological Science, 9(3): 75-78. DOI: https://doi. org/10.1111/1467-8721.00064

Bandura, A, Adams, NE and Beyer, J. 1977. Cognitive processes mediating behavioral change. Journal of Personality and Social Psychology, 35(3): 125-139. DOI: https://doi.org/10.1037/0022-3514.35.3.125

Bauer, MW, Petkova, K and Boyadjieva, P. 2000. Public knowledge of and attitudes to Science: Alternative measures that may end the "science war." Science, Technology and Human Values, 25(1): 30-51. DOI: https://doi.org/10.1177/016224390002500102

Becker-Klein, R, Peterman, K and Stylinski, C. 2016. Embedded assessment as an essential method for understanding public engagement in citizen science. Citizen Science: Theory and Practice, 1(1). DOI: https:// doi.org/10.5334/cstp.15

Becker, M, Caminiti, S, Fiorella, D, Francis, L, Gravino, P, Haklay, M (Muki), Hotho, A, Loreto, V, Mueller, J, Ricchiuti, F, Servedio, VDP, Sîrbu, A and Tria, F. 2013. Awareness and learning in participatory noise sensing. PLOS ONE, 8(12): e81638. DOI: https://doi. org/10.1371/journal.pone.0081638

Bela, G, Peltola, T, Young, JC, Balázs, B, Arpin, I, Pataki, G, Hauck, J, Kelemen, E, Kopperionen, L, van Herzele, A, Keune, H, Hecker, S, Suškevičs, $M$, Roy, HE, Itkonen, P, Külvik, M, László, M, Basnou, C, Pino, J and Bonn, A. 2016. Learning and the transformative potential of citizen science: Lessons from the Study of Nature. Conservation Biology, 30(5): 990999. DOI: https://doi.org/10.1111/cobi.12762 
Bell, S, Marzano, M, Cent, J, Kobierska, H, Podjed, D, Vandzinskaite, D, Reinert, H, Armaitiene, A, Grodzińska-Jurczak, M and Muršič, R. 2008. What counts? Volunteers and their organisations in the recording and monitoring of biodiversity. Biodiversity and Conservation, 17(14): 3443-3454. DOI: https:// doi.org/10.1007/s10531-008-9357-9

Berkowitz, AR, Ford, ME and Brewer, CA. 2005. A framework for integrating ecological literacy, civics literacy, and environmental citizenship in environmental education. In: Johnson, EA and Mappin, MJ (eds.), Environmental Education and Advocacy: Changing Perspectives of Ecology and Education, 227266. Cambridge University Press.

Bickman, L. 2000. Summing up program theory. New Directions for Evaluation, 2000(87): 103-112. DOI: https://doi.org/10.1002/ev.1186

Bodzin, AM. 2008. Integrating Instructional Technologies in a Local Watershed Investigation with Urban Elementary Learners. The Journal of Environmental Education, 39(2): 47-58. DOI: https://doi. org/10.3200/JOEE.39.2.47-58

Bonney, R. 2004. Understanding the process of research. In: Chittenden, D, Farmelo, G and Lewenstein, BV (eds.), Creating Connections: Museums and the Public Understanding of Current Research, 199-210. Walnut Creek, CA: AltaMira Press.

Bonney, R, Ballard, H, Jordan, R, McCallie, E, Phillips, T, Shirk, J and Wilderman, CC. 2009a. Public Participation in Scientific Research: Defining the Field and Assessing Its Potential for Informal Science Education. A CAISE Inquiry Group Report. Washington, DC: Center for Advancement of Informal Science Education (CAISE).

Bonney, R, Cooper, CB, Dickinson, J, Kelling, S, Phillips, TB, Rosenberg, KV and Shirk, J. 2009b. Citizen Science: A Developing Tool for Expanding Science Knowledge and Scientific Literacy. Bioscience, 59(11): 977984. DOI: https://doi.org/10.1525/bio.2009.59.11.9

Bonney, R, Phillips, TB, Ballard, HL and Enck, JW. 2016. Can citizen science enhance public understanding of science? Public Understanding of Science, 25(1): 2-16. DOI: https://doi.org/10.1177/0963662515607406

Braschler, B, Mahood, K, Karenyi, N, Gaston, KJ and Chown, SL. 2010. Realizing a synergy between research and education: How participation in ant monitoring helps raise biodiversity awareness in a resource-poor country. Journal of Insect Conservation, 14(1): 19-30. DOI: https://doi.org/10.1007/s10841-009-9221-6

Brewer, C. 2002. Outreach and partnership programs for conservation education where endangered species conservation and research occur. Conservation Biology, 16(1): 4-6. DOI: https://doi.org/10.1046/j.15231739.2002.01613.x

Brossard, D, Lewenstein, B and Bonney, R. 2005. Scientific knowledge and attitude change: The impact of a citizen science project. International Journal of Science Education, 27(9): 1099-1121. DOI: https://doi. org/10.1080/09500690500069483
Center for the Advancement of Informal Science Education. 2011. Principal Investigator's Guide: Managing Evaluation in Informal STEM Education Projects. Washington, DC.

Char, C, Parrish, J, Friesner, J and Dolliver, J. 2014. Promoting Rigorous Citizen Science: Coastal Observation and Seabird Survey Team (COASST) Evaluation Report on Citizen Impact. Seattle, WA: University of Washington.

Chen, H-T. 2005. Theory-Driven Evaluation. In: Mathison, S (ed.), Encyclopedia of Evaluation. SAGE Publications, Inc. DOI: https://doi.org/10.4135/9781412950558. n542

Clary, EG and Snyder, M. 1999. The motivations to volunteer: Theoretical and practical considerations. Current Directions in Psychological Science, 8(5): 156159. DOI: https://doi.org/10.1111/1467-8721.00037

Clary, EG, Snyder, M, Ridge, RD, Copeland, J, Stukas, AA, Haugen, $\mathbf{J}$ and Miene, P. 1998. Understanding and assessing the motivations of volunteers: A functional approach. Journal of Personality and Social Psychology, 74(6): 1516-1530. DOI: https://doi. org/10.1037/0022-3514.74.6.1516

Cooper, CB, Dickinson, J, Phillips, TB and Bonney, R. 2007. Citizen Science as a Tool for Conservation in Residential Ecosystems. Ecology and Society, 12(2): 11. [online] URL: http://www.ecologyandsociety.org/ vol12/iss2/art11/.

Cornwell, ML and Campbell, LM. 2012. Co-producing conservation and knowledge: Citizen-based sea turtle monitoring in North Carolina, USA. Social Studies of Science, 42(1): 101-120. DOI: https://doi. org/10.1177/0306312711430440

Cosquer, A, Raymond, $\mathbf{R}$ and Prevot-Julliard, A-C. 2012. Observations of everyday biodiversity: A new perspective for conservation? Ecology and Society, 17(4). DOI: https://doi.org/10.5751/ES-04955170402

Crain, R, Cooper, C and Dickinson, JL. 2014. Citizen science: A tool for integrating studies of human and natural systems. Annual Review of Environment and Resources, 39(1): 641-665. DOI: https://doi. org/10.1146/annurev-environ-030713-154609

Crall, AW, Jordan, R, Holfelder, K, Newman, GJ, Graham, J and Waller, DM. 2012. The impacts of an invasive species citizen science training program on participant attitudes, behavior, and science literacy. Public Understanding of Science, 22(6): 745-764. DOI: https://doi.org/10.1177/0963662511434894

Crall, AW, Newman, GJ, Stohlgren, TJ, Holfelder, KA, Graham, J and Waller, DM. 2011. Assessing citizen science data quality: An invasive species case study: Assessing citizen science data quality. Conservation Letters, 4(6): 433-442. DOI: https://doi.org/10.1111/ j.1755-263X.2011.00196.X

Cronin, DP and Messemer, JE. 2013. Elevating adult civic science literacy through a renewed citizen science paradigm. Adult Learning, 24(4): 143-150. DOI: https://doi.org/10.1177/1045159513499550 
Danielsen, F, Burgess, ND, Balmford, A, Donald, PF, Funder, M, Jones, JPG, Alviola, P, Balete, DS, Blomley, T, Brashares, J, Child, B, Enghoff, M, Fjeldså, J, Holt, S, Hübertz, H, Jensen, AE, Jensen, PM, Massao, J, Mendoza, MM, Ngaga, Y, Poulsen, MK, Rueda, R, Sam, M, Skielboe, T, Stuart-Hill, G, Topp-Jørgensen, E and Yonten, D. 2009. Local participation in natural resource monitoring: A characterization of approaches. Conservation Biology, 23(1): 31-42. DOI: https://doi.org/10.1111/j.15231739.2008.01063.x

Danielsen, F, Jensen, PM, Burgess, ND, Altamirano, R, Alviola, PA, Andrianandrasana, H, Brashares, JS, Burton, AC, Coronado, I, Corpuz, N, Enghoff, M, Fjeldså, J, Funder, M, Holt, S, Hübertz, H, Jensen, AE, Lewis, R, Massao, J, Mendoza, MM, Ngaga, Y, Pipper, CB, Poulsen, MK, Rueda, RM, Sam, MK, Skielbow, T, Sørensen, M and Young, R. 2014. A multicountry assessment of tropical resource monitoring by local communities. BioScience, 64: 236-51. DOI: https://doi.org/10.1093/biosci/biu001

Devictor, V, Whittaker, RJ and Beltrame, C. 2010. Beyond scarcity: Citizen science programmes as useful tools for conservation biogeography: Citizen science and conservation biogeography. Diversity and Distributions, 16(3): 354-362. DOI: https://doi. org/10.1111/j.1472-4642.2009.00615.x

Dewey, J. 1938. Experience and education. New York: Macmillan.

De Young, R. 1993. Changing Behavior and Making It Stick: The Conceptualization and Management of Conservation Behavior. Environment and Behavior, 25(3): 485-505. DOI: https://doi. org/10.1177/0013916593253003

Engeström, Y. 1999. Activity theory and individual and social transformation. In: Miettinen, R and Punamäki, R-L (eds.), Perspectives on activity theory. Cambridge: Cambridge University Press. DOI: https://doi. org/10.1017/CBO9780511812774.003

Esmond, J, Dunlop, P and Clan, W. 2004. Developing the volunteer motivation inventory to assess the underlying motivational drives of volunteers in Western Australia. Perth: Clan WA.

Evans, C, Abrams, E, Reitsma, R, Roux, K, Salmonsen, L and Marra, PP. 2005. The Neighborhood Nestwatch Program: Participant outcomes of a citizen-science ecological research project. Conservation Biology, 19(3): 589-594. DOI: https://doi.org/10.1111/j.15231739.2005.00s01.x

Falk, JH and Dierking, LD. 2003. Lessons without Limit: How free-choice learning is transforming education. Lanham, MD: Rowman Altamira.

Falk, JH, Storksdieck, M and Dierking, LD. 2007. Investigating public science interest and understanding: Evidence for the importance of free-choice learning. Public Understanding of Science, 16(4): 455-469. DOI: https://doi.org/10.1177/0963662506064240

Fenichel, M and Schweingruber, HA. 2010. Surrounded by science: Learning science in informal environments. Washington, DC: National Academies Press.
Fernandez-Gimenez, ME, Ballard, HL and Sturtevant, VE. 2008. Adaptive management and social learning in collaborative and community-based monitoring: A study of five community-based forestry organizations in the western USA. Ecology and Society, 13(2): 4. DOI: https://doi.org/10.5751/ES-02400-130204

Fishbein, M and Ajzen, I. 1975. Belief, attitude, intention, and behavior: An introduction to theory and research. Reading, MA: Addison-Wesley Publishing Company.

Flagg, B. 2016. Contribution of multimedia to girls' experience of citizen science. Citizen Science: Theory and Practice, 1(2). DOI: https://doi.org/10.5334/ cstp. 51

Friedman, AJ, Allen, S, Campbell, PB, Dierking, LD, Flagg, BN, Garibay, C, Korn, R, Silverstein, G and Ucko, DA. 2008. Framework for evaluating impacts of informal science education projects. National Science Foundation Workshop.

Funnell, SC. 2000. Developing and using a program theory matrix for program evaluation and performance monitoring. New Directions for Evaluation, 2000(87): 91-101. DOI: https://doi.org/10.1002/ev.1185

Funnell, SC and Rogers, PJ. 2011. Purposeful program theory: Effective use of theories of change and logic models, 31. John Wiley and Sons.

Heimlich, J and Ardoin, N. 2008. Understanding behavior to understand behavior change: A literature review. Environmental Education Research, 14(3): 215-237. DOI: https://doi. org/10.1080/13504620802148881

Hidi, S and Renninger, KA. 2006. The four-phase model of interest development. Educational Psychologist, 41(2): 111-127. DOI: https://doi.org/10.1207/ s15326985ep4102_4

Hiller, SE. 2012. The impact of a citizen science program on student achievement and motivation: A social cognitive career perspective. Thesis (PhD). George Mason University.

Hobbs, SJ and White, PCL. 2012. Motivations and barriers in relation to community participation in biodiversity recording. Journal for Nature Conservation, 20(6): 364-373. DOI: https://doi.org/10.1016/j. jnc.2012.08.002

Hungerford, HR and Volk, TL. 1990. Changing learner behavior through environmental education. The Journal of Environmental Education, 21(3): 8-21. DOI: https://doi.org/10.1080/00958964.1990.10753743

Jackson, CB, Osterlund, C, Mugar, G, Hassman, KD and Crowston, K. 2014. Motivations for sustained participation in crowdsourcing: Case studies of citizen science on the role of talk. IEEE, 1624-1634. DOI: https://doi.org/10.1109/HICSS.2015.196

Jordan, RC, Ballard, HL and Phillips, TB. 2012. Key issues and new approaches for evaluating citizenscience learning outcomes. Frontiers in Ecology and the Environment, 10(6): 307-309. DOI: https://doi. org/10.1890/110280

Jordan, RC, Gray, SA, Howe, DV, Brooks, WR and Ehrenfeld, JG. 2011. Knowledge gain and behavioral change in citizen-science programs: Citizen-scientist 
knowledge gain. Conservation Biology, 25(6): 1148-1154. DOI: https://doi.org/10.1111/j.1523 1739.2011.01745.x

Kaplan, S. 1995. The restorative benefits of nature: Toward an integrative framework. Journal of Environmental Psychology, 15(3): 169-182. DOI: https://doi. org/10.1016/0272-4944(95)90001-2

Kellert, SR and Wilson, EO. 1993. The biophilia hypothesis. Washington, DC: Island Press.

Kolb, DA. 1984. Experiential Learning: Experience as the Source of Learning and Development (1st ed.). Englewood Cliffs, N.J.: Prentice Hall.

Kollmuss, A and Agyeman, J. 2002. Mind the gap: Why do people act environmentally and what are the barriers to pro-environmental behavior? Environmental Education Research, 8(3): 239-260. DOI: https://doi. org/10.1080/13504620220145401

Kosmala, M, Wiggins, A, Swanson, A and Simmons, B. 2016. Assessing data quality in citizen science. Frontiers in Ecology and the Environment, 14(10): 551560. DOI: https://doi.org/10.1002/fee.1436

Kountoupes, DL and Oberhauser, KS. 2008. Citizen science and youth audiences: Educational outcomes of the Monarch Larva Monitoring Project. Journal of Community Engagement and Scholarship, 1(1): 10-20.

Krasny, ME and Bonney, R. 2005. Environmental education through citizen science and participatory action research. In: Johnson, E and Mappin, M (eds.), Environmental education and advocacy: Changing perspectives of ecology and education, 292-319. Cambridge, UK: Cambridge University Press.

Lave, J and Wenger, E. 1991. Situated learning: Legitimate peripheral participation. Cambridge: Cambridge University Press. DOI: https://doi.org/10.1017/ CBO9780511815355

Lederman, NG. 1992. Students' and teachers' conceptions of the nature of science: A review of the research. Journal of Research in Science Teaching, 29(4): 331-359. DOI: https://doi.org/10.1002/ tea.3660290404

Lederman, NG. 1999. EJSE Editorial: The state of science education: Subject matter without context. Electronic Journal of Science Education, 3(2).

Lederman, NG, Abd-El-Khalick, F, Bell, RL and Schwartz, RS. 2002. Views of nature of science questionnaire: Toward valid and meaningful assessment of learners' conceptions of nature of science. Journal of Research in Science Teaching, 39(6): 497-521. DOI: https://doi.org/10.1002/tea.10034

Lederman, NG, Schwartz, RS, Abd-El-Khalick, F and Bell, RL. 2001. Pre-service teachers' understanding and teaching of nature of science: An intervention study. Canadian Journal of Science, Mathematics and Technology Education, 1(2): 135-160. DOI: https://doi. org/10.1080/14926150109556458

Lewandowski, E and Oberhauser, K. 2017. Butterfly citizen scientists in the United States increase their engagement in conservation. Biological Conservation, 208: 106-112. DOI: https://doi.org/10.1016/j.biocon.2015.07.029
Maltese, AV and Tai, RH. 2010. Eyeballs in the fridge: Sources of early interest in science. International Journal of Science Education, 32(5): 669-685. DOI: https://doi.org/10.1080/09500690902792385

McCaffrey, RE. 2005. Using citizen science in urban bird studies. Urban Habitats, 3(1): 70-86.

McCallie, E, Bell, L, Lohwater, T, Falk, JH, Lehr, JL, Lewenstein, BV and Wiehe, B. 2009. Many experts, many audiences: Public engagement with science and informal science education. (A CAISE Inquiry Group Report). Washington, DC: Center for Advancement of Informal Science Education (CAISE).

McKinley, DC, Miller-Rushing, AJ, Ballard, HL, Bonney, R, Brown, H, Cook-Patton, SC, Evans, DM, French, RA, Parrish, JK, Phillips, TB, Ryan, SF, Shanley, LA, Shirk, JL, Stepenuck, KF, Weltzin, JF, Wiggins, A, Boyle, OD, Briggs, RD, Chapin, SF, III, Hewitt, DA, Preuss, PW and Soukup, MA. 2016. Citizen science can improve conservation science, natural resource management, and environmental protection. Biological Conservation, 208: 15-28. DOI: https://doi.org/10.1016/j.biocon.2016.05.015

Mejlgaard, N and Stares, S. 2010. Participation and competence as joint components in a cross-national analysis of scientific citizenship. Public Understanding of Science, 19(5): 545-561. DOI: https://doi. org/10.1177/0963662509335456

Meyer, NJ, Scott, S, Strauss, AL, Nippolt, PL, Oberhauser, KS and Blair, RB. 2014. Citizen science as a REAL environment for authentic scientific inquiry. Journal of Extension, 52(4).

Miller-Rushing, A, Primack, R and Bonney, R. 2012. The history of public participation in ecological research. Frontiers in Ecology and the Environment, 10(6): 285290. DOI: https://doi.org/10.1890/110278

Mugar, G, Østerlund, C, Hassman, KD, Crowston, K and Jackson, CB. 2014. Planet hunters and seafloor explorers: legitimate peripheral participation through practice proxies in online citizen science. CSCW '14 Proceedings of the 17th ACM Conference on Computer Supported Cooperative Work and Social Computing, 109-119. New York: ACM Press. DOI: https://doi. org/10.1145/2531602.2531721

National Academies of Sciences, Engineering, and Medicine. 2016. Science Literacy: Concepts, Contexts, and Consequences. In: Snow, CE and Dibner, KA (eds.). Washington, D.C.: National Academies Press. DOI: https://doi.org/10.17226/23595

National Research Council. 1996. National Science Education Standards. Washington, DC: National Academies Press.

National Research Council. 2009. Learning science in informal environments: People, places, and pursuits. Washington, DC: National Academies Press. DOI: https://doi.org/10.17226/12190

National Science Board. 2014. Science and engineering indicators 2014. Arlington, VA: National Science Foundation (NSB 14-01).

NGSS Lead States. 2013. Next generation science standards: For states, by states. Washington, D.C: National AcademiesPress.DOI:https://doi.org/10.17226/18290 
Nov, O, Arazy, 0 and Anderson, D. 2014. Scientists@ Home: What drives the quantity and quality of online citizen science participation? PLOS ONE, 9(4): e90375. DOI: https://doi.org/10.1371/journal.pone.0090375

Oberhauser, K and Prysby, MD. 2008. Citizen science: Creating a research army for conservation. American Entomologist, 54(2): 103-104. DOI: https://doi. org/10.1093/ae/54.2.103

Osbaldiston, R and Schott, JP. 2012. Environmental sustainability and behavioral science meta-analysis of proenvironmental behavior experiments. Environment and Behavior, 44(2): 257-299. DOI: https://doi. org/10.1177/0013916511402673

Osborne, J, Simon, S and Collins, S. 2003. Attitudes towards science: A review of the literature and its implications. International Journal of Science Education, 25(9): 1049-1079. DOI: https://doi. org/10.1080/0950069032000032199

Overdevest, C, Orr, CH and Stepenuck, K. 2004. Volunteer stream monitoring and local participation in natural resource issues. Human Ecology Review, 11(2): 177-185.

Phillips, T, Ferguson, M, Minarchek, M, Porticella, N and Bonney, R. 2014. User's Guide for Evaluating Learning Outcomes in Citizen Science. Ithaca, NY: Cornell Lab of Ornithology. Retrieved from: http://cdn1.safmc.net/wp-content/ uploads/2016/11/28101058/CitizenScienceUsersGuide_Evaluation_2014.pdf.

Phillips, TB, Bonney, R and Shirk, J. 2012. What is our impact? Toward a unified framework for evaluating outcomes of citizen science participation. In: Dickinson, JL and Bonney, R (eds.), Citizen science: Public participation in environmental research, 82-95. Ithaca, NY: Cornell University Press. DOI: https://doi. org/10.7591/cornell/9780801449116.003.0006

Phillips, TB, Lewenstein, BV and Bonney, R. 2006. A case study of citizen science. In: Cheng, D, Metcalf, J and Schiele, B (eds.), At the human scale, international practices in science communication, 317-334. Beijing: Science Press.

Price, CA and Lee, H-S. 2013. Changes in participants' scientific attitudes and epistemological beliefs during an astronomical citizen science project. Journal of Research in Science Teaching, 50(7): 773-801. DOI: https://doi.org/10.1002/tea.21090

Raddick, MJ, Bracey, G, Carney, K, Gyuk, G, Borne, K, Wallin, J and Jacoby, S. 2009. Citizen science: Status and research directions for the coming decade. $A G B$ Stars and Related Phenomenastro 2010: The Astronomy and Astrophysics Decadal Survey, 2010, 46.

Raddick, MJ, Bracey, G, Gay, PL, Lintott, CJ, Murray, P, Schawinski, K, Szalay, AS and Vandenberg, J. 2010. Galaxy Zoo: Exploring the motivations of citizen science volunteers. Astronomy Education Review, 9(1). DOI: https://doi.org/10.3847/AER2009036

Reed, J, Raddick, MJ, Lardner, A and Carney, K. 2013. An exploratory factor analysis of motivations for participating in Zooniverse, a collection of virtual citizen science projects. In: 2013 46th Hawaii International Conference on System Sciences
(HICSS), 610-619. DOI: https://doi.org/10.1109/ HICSS.2013.85

Roth, W-M and Lee, S. 2002. Scientific literacy as a collective praxis. Public Understanding of Science, 11(1): 33-56. DOI: https://doi.org/10.1088/0963$6625 / 11 / 1 / 302$

Roth, W-M and Lee, S. 2004. Science education as/for participation in the community. Science Education, 88(2): 263-291. DOI: https://doi.org/10.1002/ sce. 10113

Roth, W-M and Roychoudhury, A. 1993. The concept map as a tool for the collaborative construction of knowledge: A microanalysis of high school physics students. Journal of Research in Science Teaching, 30(5): 503-534. DOI: https://doi.org/10.1002/tea.3660300508

Rotman, D, Preece, J, Hammock, J, Procita, K, Hansen, D, Parr, C, Lewis, D and Jacobs, D. 2012. Dynamic changes in motivation in collaborative citizen-science projects. Presented at the Computer Supported Cooperative Work 2012, 217-226. Seattle, Washington: ACM Press. DOI: https://doi. org/10.1145/2145204.2145238

Ryan, RM and Deci, EL. 2000a. Intrinsic and extrinsic motivations: Classic definitions and new directions. Contemporary Educational Psychology, 25(1): 54-67. DOI: https://doi.org/10.1006/ceps.1999.1020

Ryan, RM and Deci, EL. 2000b. Self-determination theory and the facilitation of intrinsic motivation, social development, and well-being. American Psychologist, 55(1): 68-78. DOI: https://doi. org/10.1037/0003-066X.55.1.68

Schmeller, DS, Henry, P-Y, Julliard, R, Gruber, B, Clobert, J, Dziock, F, Lengyel, S, Nowicki, P, Déri, E, Budrys, E, Kull, T, Tali, K, Bauch, B, Settele, J, van Swaay, C, Kobler, A, Babij, V, Papastergiadou, E and Henle, K. 2009. Advantages of volunteer-based biodiversity monitoring in Europe. Conservation Biology, 23(2): 307-316. DOI: https://doi.org/10.1111/ j.1523-1739.2008.01125.x

Schneider, B and Cheslock, N. 2003. Measuring results. San Francisco, CA: Coevolution Institute.

Schultz, PW. 2011. Conservation means behavior. Conservation Biology, 25(6): 1080-1083. DOI: https:// doi.org/10.1111/j.1523-1739.2011.01766.x

Schunk, DH. 1991. Self-efficacy and academic motivation. Educational Psychologist, 26(3-4): 207-231. DOI: https://doi.org/10.1080/00461520.1991.9653133

Shamos, MH. 1995. The myth of scientific literacy. New Brunswick, NJ: Rutgers University Press.

Shirk, JL, Ballard, HL, Wilderman, CC, Phillips, T, Wiggins, A, Jordan, R, McCallie, E, Minarchek, M, Lewenstein, BV, Krasny, ME and Bonney, R. 2012. Public participation in scientific research: A framework for deliberate design. Ecology and Society, 17(2). DOI: https://doi.org/10.5751/ES-04705-170229

Sickler, J, Cherry, TM, Allee, L, Smyth, RR and Losey, J. 2014. Scientific value and educational goals: Balancing priorities and increasing adult engagement in a citizen science project. Applied Environmental Education and Communication, 13(2): 109-119. DOI: https://doi.org/ 10.1080/1533015X.2014.947051 
Stern, MJ, Powell, RB and Ardoin, NM. 2008. What difference does it make? Assessing outcomes from participation in a residential environmental education program. The Journal of Environmental Education, 39(4): 31-43. DOI: https://doi.org/10.3200/ JOEE.39.4.31-43

Stern, PC. 2000. New environmental theories: Toward a coherent theory of environmentally significant behavior. Journal of Social Issues, 56(3): 407-424. DOI: https://doi.org/10.1111/0022-4537.00175

Sturgis, P and Allum, N. 2004. Science in society: Reevaluating the deficit model of public attitudes. Public Understanding of Science, 13(1): 55-74. DOI: https:// doi.org/10.1177/0963662504042690

Sullivan, BL, Wood, CL, Iliff, MJ, Phillips, TB, Fink, D and Kelling, S. 2009. eBird: A citizen-based bird observation network in the biological sciences. Biological Conservation, 142(10): 2282-2292. DOI: https://doi.org/10.1016/j.biocon.2009.05.006

Tai, RH, Qi Liu, CQ, Maltese, AV and Fan, X. 2006. Planning early for careers in science. Science, 312(5777): 1143-1144. DOI: https://doi.org/10.1126/ science. 1128690

Theobald, EJ, Ettinger, AK, Burgess, HK, DeBey, LB, Schmidt, NR, Froehlich, HE, Parrish, JK, et al. 2015. Global change and local solutions: Tapping the unrealized potential of citizen science for biodiversity research. Biological Conservation, 181: 236-244. DOI: https://doi.org/10.1016/j.biocon.2014.10.021

Thompson, S and Bonney, R. 2007. Evaluating the impacts of participation in an online citizen science project: A mixed-methods approach. In: Trant, J and Bearman, D (eds.), Museums and the web 2007: Selected papers from an international conference, 187-199. Toronto: Archives and Museum Informatics.

Toomey, AH and Domroese, MC. 2013. Can citizen science lead to positive conservation attitudes and behaviors? Human Ecology Review, 20(1): 50-62, 67.

Trautmann, N, Shirk, J, Fee, J and Krasny, ME. 2012. Who poses the question? Using citizen science to help K-12 teachers meet the mandate for inquiry. In: Dickinson, JL and Bonney, R (eds.), Citizen science: Public participation in environmental research, 179191. Ithaca, NY: Cornell University Press. DOI: https:// doi.org/10.7591/cornell/9780801449116.003.0013

Trumbull, DJ, Bonney, R, Bascom, D and Cabral, A. 2000. Thinking scientifically during participation in a citizen-science project. Science Education, 84(2):
265-275. DOI: https://doi.org/10.1002/(SICI)1098237X(200003)84:2<265::AID-SCE7>3.0.CO;2-5

Trumbull, DJ, Bonney, R and Grudens-Schuck, N. 2005. Developing materials to promote inquiry: Lessons learned. Science Education, 89(6): 879-900. DOI: https://doi.org/10.1002/sce.20081

Ulrich, R. 1993. Biophilia, biophobia, and natural landscapes. In: Kellert, SR and Wilson, EO (eds.), The biophilia hypothesis, 73-137. Washington, DC: Island Press.

Vining, J, Ebreo, A, Bechtel, RB and Churchman, A. 2002. Emerging theoretical and methodological perspectives on conservation behaviour. In: Bechtel, $\mathrm{R}$ and Churchman, A (eds.), New handbook of environmental psychology, 541-558. New York: Wiley.

Vygotsky, LS and Cole, M. 1978. Mind in society: the development of higher psychological processes. Cambridge: Harvard University Press.

Weinberg, RS, Gould, D and Jackson, A. 1979. Expectations and performance: An empirical test of Bandura's self-efficacy theory. Journal of Sport Psychology, 1(4): 320-331.

Wells, NM and Lekies, KS. 2012. Children and nature: Following the trail to environmental attitudes and behavior. In: Dickinson, JL and Bonney, R (eds.), Citizen science: Public participation in environmental research, 201-213. Ithaca, NY: Cornell University Press. DOI: https://doi.org/10.7591/cornell/9780801449116.003.0015

Wenger, E. 1998. Communities of practice: Learning, meaning, and identity. Cambridge: Cambridge University Press. DOI: https://doi.org/10.1017/ CB09780511803932

Wilson, EO. 1984. Biophilia: The human bond with other species. Cambridge, MA: Harvard University Press.

Wing, S, Horton, RA, Marshall, SW, Thu, K, Tajik, M, Schinasi, L and Schiffman, SS. 2008. Air pollution and odor in communities near industrial swine operations. Environmental Health Perspectives, 116(10): 1362-1368. DOI: https://doi.org/10.1289/ ehp. 11250

Wright, DR, Underhill, LG, Keene, M and Knight, AT. 2015. Understanding the motivations and satisfactions of volunteers to improve the effectiveness of citizen science programs. Society and Natural Resources, 28(9): 1013-1029. DOI: https://doi.org/10.1080/089 41920.2015.1054976

How to cite this article: Phillips, T, Porticella, N, Constas, M and Bonney, R. 2018. A Framework for Articulating and Measuring Individual Learning Outcomes from Participation in Citizen Science. Citizen Science: Theory and Practice, 3(2): 3, pp. 1-19, DOI: https://doi.org/10.5334/cstp.126

Submitted: 03 October 2017 Accepted: 31 May 2018 Published: 28 August 2018

Copyright: ( $) 2018$ The Author(s). This is an open-access article distributed under the terms of the Creative Commons Attribution 4.0 International License (CC-BY 4.0), which permits unrestricted use, distribution, and reproduction in any medium, provided the original author and source are credited. See https://creativecommons.org/licenses/by/4.0/.

$\mathrm{u}[\quad$ Citizen Science: Theory and Practice is a peer-reviewed open access journal published by Ubiquity Press. 